\title{
Maturity Models of Education Information Systems and Technologies: A Systematic Literature Review
}

\author{
João Vidal Carvalho \\ Politécnico do Porto / CEOS.PP \\ Porto, Portugal \\ cajvidal@iscap.ipp.pt
}

\author{
Rui Humberto Pereira \\ Politécnico do Porto / CEOS.PP \\ Porto, Portugal \\ rhp@iscap.ipp.pt
}

\author{
Álvaro Rocha \\ Universidade de Coimbra \\ Coimbra, Portugal \\ amrocha@dei.uc.pt
}

\begin{abstract}
Maturity models (MM) have been introduced, over the last five decades, as guides and references for the information system management in organizations from different sectors of activities. In the education sector, MM have also been used to evaluate higher education institutions (HEI) in several dimensions, such as ICT, management, process management, course curricula, course/HEI accreditation, e/m-learning, online courses and pedagogical strategies. The HEI have an enormous complexity due to the specificity and quantity of their processes, demanding capable information systems (IS) and tools to manage these IS. Based on the guidelines of a methodology for a systematic literature review, the MM of different subareas of education are identified and categorized in this paper. For each MM associated with HEI IS, it is identified the methodology of development and validation, as well as the scope, stages and their characteristics by dimensions. This study resulted in the need to develop a MM for IS that supports HEI in their core business activities and management.
\end{abstract}

Keywords - Stages of Growth, Maturity Models, Higher Education Institutions, Education Information Systems, Management.

\section{INTRODUCTION}

In the last decades, we have seen many changes in the HEI. In the past, higher education was much restricted in terms of capacity of students. The massification of this kind of education, puts HEI under enormous pressure for providing the required and capable means. In addition, the new teaching paradigms (Bologna Treaty), the new perspective of the student as a "costumer", the opening of universities to enterprises, in terms of knowledge transference, the HEI rankings and HEI competition, forced the HEI to reinvent higher education and adopt agile management methodologies, in order to be capable of adapting to the constant environment changes.

It is generally accepted that Information Systems and Technologies (IST) provide the basis for a successful management for any kind of institution. The HEI are not an exception. Zhihua and Zhaojun [1] suggest that schools that are more e-mature, improved their performance levels significantly and more quickly than those that are not. Saiti and Prokopiadou [2] observe that the usage of new technologies in school administration is vital to upgrade administrative processes. In fact, HEI in order to achieve their mission of producing and transferring knowledge for society, involving teaching and scientific activities, become complex and interconnected systems, in which Information Technologies (IT) support complex processes, control and management activities. The quantity of distinct and complex processes requires an information ecosystem composed by several interoperable subsystems.

The HEI have faced their new reality implementing Information Ecosystems (IE) composed by a large spectrum of platforms, such as: Academic Management ERP, Financial ERP, Student Relationship Management (SRM), Learning Management System (LMS), Content Management Systems (CMS), Survey tools, Business Intelligence (BI), Current Research Information System (CRIS) and repository of publications, among many others. Due to this scenario, HEI must have an integrated vision of all these individual platforms as a unique information system capable of supporting their transversal organizational processes. Managing such complex ecosystems of platforms and processes, requires powerful tools to evaluate and guide HEI in terms of capability to support these organizational processes and high level of IS integration. According to Manjula and Vaideeswaran [3] the increasing of competency in IT and educational sectors, needs a process maturity evaluation methodology for educational organization. Thus, we started our research work in the scope of MM of those Information Ecosystems.

In our research, we intend to discover if there are tools to manage such ecosystems of IS, in terms of MM. In this preliminary stage of our research, a literature review was done, in order to find any eventual gaps on the existing models of maturity. After following a systematic methodology of literature review, we consider a few set of research works that we consider as related with ours. Then, we focused our analysis on these works in order to understand their capability of answering to the requisites of those tools. Thus, this article intends to contribute for this research field by answering to these questions, giving to its readers, a state of the art of those MM in the scope of HEI.

In the next section, is presented a brief overview of the MM in IS area (second section). Then, in the third section, the research methodology adopted for the literature review is described. The fourth section presents the results of the literature review, that is, the MM for education IST are described and categorized. Finally, in the fifth section, is presented the summary and closing remarks. 


\section{MATURITY MODELS IN IST MANAGEMENT}

The concept of MM is increasingly applied in the IS field, both as an approach needed for continuous improvement [4] as for its evaluation [5]. Since its initial conception in the early 1970s [6, 7], a multitude of different instances have been developed in science and practice. However, as organizations face constant pressures to achieve and maintain competitive advantage by inventing and reinventing new products and services, reduce costs and time to market, and at the same time improve the quality, there is a continuing need for development of new MM, since they help the decision makers to achieve these goals [8]. On the other hand, through the incorporation of formalism in the improvement of activities, decision makers within organizations can determine if the potential benefits are being achieved or not.

The MM are available to respond to many different challenges. These models provide information for organizations to address the problems and challenges in a structured way, providing both a reference point to assess the capabilities as a roadmap for improving [9]. In other words, the $\mathrm{MM}$ offer an orientation through an evolutionary process, incorporating the procedures for improving activities [10].

Various MM have been proposed over time, both for the development of individuals and for the general evolution of organizations or the particular evolution of the IS management function. These models mainly differ in terms of a number of stages, variables of evolution and focus areas [10-12]. Each of these models identifies certain characteristics that specifically define the objectives of the next stage of growth. These types of models can be applied situationally within education in order to strategically planning for IST maturation, based on the degree of alignment between the educational organization (e.g. HEI) strategy and the selected growth path, as well as associated investments and improvement activities.

In the literature review carried out in this project, as well as in complementary studies, it was verified that there is no comprehensive and detailed HEI MM that assesses the maturity of IS in its various aspects. In fact, a content analysis of scientific articles, manuals, white papers, reports and websites, all with information on $\mathrm{MM}$ in the area of education, also revealed the inexistence of $\mathrm{MM}$ of dimensions or influence factors that consider the same with different weights compared to their relative importance.

In view of these constraints, it was considered opportune to develop a research project that would contribute to an increase of knowledge about the MM applied to HEI, in order to spread an improvement in the practice of evaluating and promoting the maturity of their IS. Based on the description of the problem, the following research question was formulated:

- Is there a model, which consists of several maturityinfluencing factors and maturity stages, that can be applied to IST of Higher Education Institutions?

\section{Methodology AdOPTED FOR THE LITERATURE REVIEW}

Aiming to conduct a comprehensive and wide literature review, it was necessary to define a strategy [13] in order to identify and analyse systematically the available literature on MM of education IST. An initial review provided criteria to choose the approach and establish the strategies to be applied to this project.

The first strategy by Webster and Watson [14] suggests a structured approach in three basic steps: to identify the relevant literature in main sources (i.e. "leading journals") and recognized conferences. Then, the authors suggest conducting a search in the reference section of the studies identified in the first step in order to identify potential works related; finally, it is suggested the search via Web of Science of works which cite the works identified in the previous two steps.

The second strategy, proposed by Tranfield et al.[15], suggests five steps for a systematic review of the literature. The first stage defines terms, keywords and combinations to be used as criteria to be applied in the literature review. A second phase is to identify relevant works that contain the keywords and terms defined above. In the third phase, it is carried out an assessment of identified papers and made a selection of works that meet certain criteria of quality. In the fourth phase, it must be extracted the relevant information from the selected literature. Finally, in the fifth phase a synthesis of data is done. With regard to Tranfield et al.'s approach, no clear procedure was found for the identification of relevant work in the second phase. So, this phase of Tranfield et al.'s approach was replaced by the three basic steps described by Webster and Watson.

\section{Main keywords}

Therefore, the terms and keywords were defined as literature searching criteria, taking in account that most of the relevant literature on MM of educational IST is written in English. "Maturity Model" and "Educational" combined in several research contexts, namely in title (TI), abstract (AB) and subject (SU) were used for the search iterations.

TI "maturity model" AND TI education OR AB "maturity model" AND AB education OR SU "maturity model" AND SU education

The searching criteria were applied to the literature review. Given that Tranfield et al. [15] did not suggest any procedure for this stage, it was followed the approach proposed by Webster and Watson [14] introducing two changes: in the first step, the main sources were replaced by major web platforms of scientific literature; and in the third step of this approach, b-on ${ }^{1}$ platform was replaced by the search engines Google and Google Scholar.

\section{Data sources and searches}

The literature search was performed for the studies published in academic journals and conference proceedings until January 
2018. In order to simplify the search process, we opted for using b-on platform that aggregate the results of search in multi databases such as: ACM digital library, ISI Web of Knowledge, SCOPUS, SpringerLink, Elsevier/Science Direct and IEEE Computer Society Digital Library. Afterwards, we proceeded to a data analysis to identify related references, as suggested by Webster and Watson [14]. Finally, given that the disclosure of much of the information on MM of education IST has been accomplished through technical reports, research and white papers projects, we move to a more extended search through the search engine Google Scholar and Google to ensure identification of other relevant work for the study.

\section{Inclusion and Exclusion criteria}

The following inclusion criteria (at least one) were used:

- The study proposes or presents a complete MM from the educational area with the description of its different stages.

- The study proposes or presents a way to evaluate the maturity of an education IST.

- The study proposes a MM that, being of the educational area, focus on the IS of the educational institutions.

The following exclusion criteria were used:

- The study proposes or presents an incomplete MM, still in an embrionary stage.

- The study proposes or presents an application in an educational context of an existing MM.

The study selection was performed by one of the authors in two stages. In the first stage, all potentially relevant studies were selected based on titles, abstracts, and subject and in consideration of the inclusion and exclusion criteria. In the second stage, each of the studies selected from the previous stage were read in full and analysed again, according to the inclusion and exclusion criteria. In addition, the related works cited by these studies were evaluated and included in the review if they were considered relevant to the search area.

\section{Data extraction and quality assessment}

Data extraction and quality assessment were undertaken by one author and confirmed by another. Data related to research approach, scope, stages, dimensions, evaluation tools and potentialities and fragility were extracted and categorized.

\section{Data synthesis and analysis}

The extracted data was tabulated and summarized, any disagreement was resolved with a discussion and, when necessary, by involving a third author. The extracted data was grouped into the following topics: name, research approach, scope, stages, dimensions, evaluation tools, year and authors. Finally, we summarized potentialities and the fragilities identified in the reviewed articles.

Fig. 1 presents the refinement steps and resulting number of articles after applying the Tranfield et al.[15] and Webster and Watson [14] strategies.

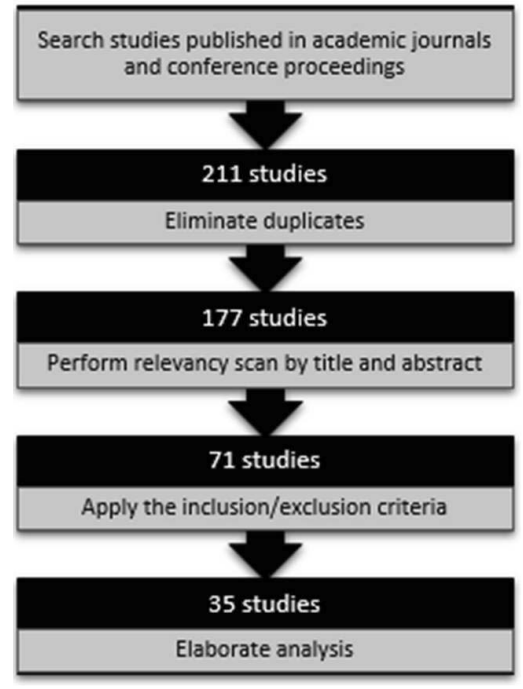

Fig. 1 - The refinement steps and resulting number of articles

\section{RESULTS AND COMPARATION}

As a result of this literature review, it was found that the MM for education IST are developed involving different types of entities, including national and international education companies, research organizations as well as academic experts in this domain.

It was also found that there are two approaches: in one hand, the highly specialized models that have focused in one education subsystem and on the other hand, the more comprehensive models, i.e. models representing the educational institution IS as a whole. Also, it was found that most of the analysed MM does not disclose the design process nor the research options for development and validation, thus compromising the researcher work.

It appears that CMM [4] and CMMI [16] his successor, is the reference model for the design of $\mathrm{MM}$ in the education sector. This model has served as inspiration for dozens of MM in the various areas of IST, and the area of education is no exception. Regarding the number of maturity stages, there are models from 3 stages as the case of eQETIC [17] up to 8 stages (ICTMMEI-DV [18]).

In the literature review mentioned above, the following MM were identified in the educational domain:

- e-learning (eMM[19], [20], ELMM[21], MLMM[22], Aol-CMM[23], IA-LMM[24])

- Online course (OCDMM[25], OCQMM[26], eQETIC[17])

- Strategy and Learning ([27])

- Student Engagement (SESR-MM[28])

- Educate Senior Management (EIM-MM[29])

- Intelligence Training/Education ([30])

- IS Curriculum (CMMI-ISC[31], CDMM[32], ERPEDMM[33])

- Learning Process (LPMM[34], [35]) 
- Project Management (PMMM[36])

- Academic Management ([37], ITIL-ITSMM[38])

- Continuing/Quality Education (HEMM[39], [40], CMMQE[3])

- Engineering/Computation Education (EECMM[41], CEMM[42], TeaM[43], CM/sup 3/[44], [45])

- Intellectual Capital (ICMM[46])

- Web Accessibility ([47])

- Accreditation of educational institutions (MRAEIS[48])

- Green Governance (Green IT Governance[49])

- ICT in Education (ICTE-MM[50], ICTMMEI-DV[18])

Within the HEI IST domain, which is the main focus of our research, several MM have been proposed, although these models are still at an early stage of development. These models have an important focus on the management of IS of an educational institution, either in a global perspective or by defining one of its dimensions. Thus, in our literature review we considered $5 \mathrm{MM}$ which are summarized in Table 1. Besides the identification of each model and its authors, is presented the scope (within the IST domain), number of stages, research method adopted in its development, dimensions considered and the assessment tool and model that was used as reference for its development.

They all suggest attributes that the organization should possess to be positioned at each stage. However, most IST MM do not explicitly identify any assessment tool. Only the ICTEMM provide a tool to assess the fulfilment of requirements, to effectively place an organization in a certain level. Next, a brief description will be made of the MM associated with HEI.

Maturity Model for ICT in School Education (ICTE-MM) [50]: The ICTE-MM has three elements supporting educational processes: information criteria, ICT resources, and leverage domains. Changing the traditional and exclusive focus on ICT, five leverage domains are defined: Infrastructure, Educational Management, Administrators, Teachers and
Students.

Despite its large spectrum of coverage, this MM does not explicitly considers issues such as business process definition/documentation and IS capability for supporting such processes. This is a MM based on international standards for assessing the school's development regarding to the use of ICT and not a MM for accessing the IS capability for supporting the school's management and teaching/learning processes. Issues like software for academic management, financial management and teaching/learning process management are superficially approached, applying only three variables, as well as in School Management, by means of six Critical Variables, none of them covering the business process definition. We consider that there are other missing Critical Variables which are fundamental to achieve a more comprehensive MM for accessing the use of ICT in schools. Additionally, this is a generic MM for school educational processes not focused in HEI.

Capability maturity model for quality Education (CMMQE)[3]: CMM-QE is a framework for quality education assessment and process improvement with five maturity levels. The CMM-QE evaluates the Education system engineering process from the multi perspectives of academic, infrastructure, administration, facilities etc. CMM-QE use critical factors (Key Indicators) to be quantified to assess the maturity level of the Educational institutions.

Despite those authors' goals, the proposed MM is not clearly presented. Although a number of variables grouped in four measurement models covering several areas of the educational institution is referred, none of them have a concise and systematic description. Only an apparently unordered and unrelated list of characteristics is presented. In our point of view, this missing systematization of the assessed attributes compromises the reader's full understanding regarding the proposed authors' framework, as well as its applicability in the real world practice. This lack in the description of the CMM$\mathrm{QE}$, is not compensated with any previous work presenting the authors' framework. As far as we know, this model was not adopted in subsequent studies and the academic community has not significantly referenced it.

Table 1 - Summary and comparison of maturity models for High Education Institutions IST

\begin{tabular}{|c|c|c|c|c|c|c|c|}
\hline Designation & Focus & Stages & Research Method & Dimensions & $\begin{array}{l}\text { Assessment } \\
\text { Tool }\end{array}$ & $\begin{array}{l}\text { Reference } \\
\text { Model }\end{array}$ & $\begin{array}{l}\text { Author/ } \\
\text { Year }\end{array}$ \\
\hline ICTE-MM & $\begin{array}{l}\text { ICT in School } \\
\text { Education }\end{array}$ & 5 & $\begin{array}{c}\text { Pilot study } \\
\text { Survey } \\
\text { Interviews }\end{array}$ & $\begin{array}{l}\text { Educational Management, } \\
\text { Infrastructure, Administrators, } \\
\text { Teachers and Students }\end{array}$ & $\begin{array}{l}\text { web- } \\
\text { support } \\
\text { tool }\end{array}$ & CMMI & $\begin{array}{l}\text { Solar et al. } \\
2013 \text { [50] }\end{array}$ \\
\hline CMM-QE & $\begin{array}{c}\text { Process } \\
\text { improvement } \\
\text { and Quality } \\
\text { Education }\end{array}$ & 5 & $\begin{array}{l}\text { Structured equation } \\
\text { modelling / PLS } \\
\text { Questionnaires, } \\
\text { Cluster analysis } \\
\text { Analysis of variance }\end{array}$ & $\mathrm{C}_{\mathrm{C}}$ & No & CMM & $\begin{array}{l}\text { Manjula \& } \\
\text { Vaideeswaran } \\
2012[3]\end{array}$ \\
\hline OCQMM & $\begin{array}{c}\text { Online course } \\
\text { quality }\end{array}$ & 4 & $\mathrm{n} / \mathrm{d}$ & $\begin{array}{l}\text { Learning resources, teaching } \\
\text { platform, The teaching process, } \\
\text { Monitoring and evaluation }\end{array}$ & No & CMM & $\begin{array}{l}\text { Gu et al. } \\
2011 \text { [51] }\end{array}$ \\
\hline ICTMMEI-DV & $\begin{array}{l}\text { ICT Equip. } \\
\text { and use }\end{array}$ & 8 & Survey & $\begin{array}{c}\text { Institutional, Resource } \\
\text { Milestones, Potential } \\
\text { Learning Outcomes }\end{array}$ & No & - & $\begin{array}{c}\text { Bass } \\
2011[18]\end{array}$ \\
\hline eQETIC & $\begin{array}{c}\text { Online } \\
\text { Education }\end{array}$ & 3 & $\mathrm{n} / \mathrm{d}$ & $\begin{array}{c}\text { Didactic-Pedagogical, } \\
\text { Technology, Management, } \\
\text { Support, Tutorial, Evaluation }\end{array}$ & No & - & $\begin{array}{c}\text { Rossi \& } \\
\text { Mustaro } \\
2015[17]\end{array}$ \\
\hline
\end{tabular}


Online Course Quality Maturity Model Based on Evening University and Correspondence Education (OCQMM)[51]: This model, proposes to assess the quality of online courses in Evening University and Correspondence Education. OCQMM can guide the institutions that engaged in adult education to meliorate the implementary process, so that the implementation quality of online course will be improved. OCQMM divided online courses quality maturity in evening university and correspondence education into four maturity evolving ladder levels, each low-level is a basis that achieve a higher level.

We consider the proposed MM sufficiently comprehensive in terms of key areas, addressing relevant quality issues of online courses. However, there are important missing issues such as teacher motivation and pedagogical practices that are not considered. More important, we also consider insufficient the level of detail in which the six key process areas are described, making very difficult to replicate the authors' experience of testing the proposed MM in other institutions. This limitation is not mitigated by means of any other previous publication where the authors sufficiently present their model. Regarding the model systematization, the authors do not provide any methodology or analytic methods for determining the school's maturity level in each key process area. Either they provide a way for determining the maturity level of an online course or the school as a whole.

Maturity Model for ICT in Educational Institutions in Developing Countries (ICTMMEI-DV)[18]: This proposal aims to provide guidance for ICT infrastructure planning and to create a reference model to the necessary development phases for the efficient use of these resources. The model defines the ICT infrastructure resource levels required to achieve primary organizational objectives expressed in the form of student learning outcomes. The levels in this model show management, teaching and technical staff, as well as donors how to make most efficient use of ICT resources by maximizing opportunities for student learning.

Despite the lack of discussion regarding those three important levels, we can conclude that this MM is strictly focused on ICT. Issues related to management process definition and other relevant aspects of IS are not considered in this model. This MM was specially designed for education institutions of developing countries, in which the resources are very limited. Such context, is very different from the ones that exist in developed countries, making this MM not well suited for institutions in these countries. Additionally, this model intends to cover a broad type of educational levels, which have distinct educational goals. In our opinion, the author's proposal is aligned with primary educational levels, and not well suited for HEI.

eQETIC: A Maturity Model for Online Education [17]: This is a model capable of supporting steps that guide the planning, development, and maintenance of digital educational solutions. eQETIC model follows a continuous process improvement approach, whereas the implementation of processes in a developer organization of these types of solutions favours the development lifecycle and the quality of these solutions. The model allows the organization to implement the processes belonging to each level at a given time, and these levels and processes are organized in six common entities.

This model is focused on the quality of the product development process, including the learning process, the environment and aspects that condition the success of the education institution in terms of quality of the specific scope of solutions (distance education, e-learning and learning objects). Despite being a comprehensive model on such type of solutions, it does not consider other types of teaching such as blended learning and traditional face-to-face teaching, as well as facilities for students, administrative support, or other specific IS aspects of HEI in their full achievement of mission and duties.

\section{SUMMARY AND CLOSING REMARKS}

Most of the mentioned models are still in an early development stage and in a premature phase of affirmation and consolidation, being proposed by their authors through exploratory studies. In fact, few of the identified models are adopted in a large scale, nor are significantly referenced by the academic community. Additionally, most of these models are not sufficiently explicit in the way they were developed and validated, and especially because they are poorly detailed, they do not provide tools to determine the maturity stage nor structure the characteristics of maturity stages. In the case of the adoption of a tool for assessing the system's maturity, it was found that most of the models, besides focusing on the assessment of the system's maturity, pay attention to an improvement path of such maturity. However, not all have a properly systematized process to move to a higher maturity level. Also, the authors did not apply weights to each of the influencing factors (or dimensions), that is, in the assessing process of the overall maturity of education IST, all influencing factors have the same importance. Based on the analysis, it was possible to verify that no model was developed based on the guidelines of the development methodologies of MM [52-54].

Based on the collection of analysed MM focused in HEI and Education Institutions, we have categorized the founded models according five main scopes: (1) Management of the institution; (2) Process management; (3) learning and e/m-learning practices and quality; (4) course/HEI external accreditation and evaluation in terms of quality and (5) ICT.

In the literature, the identified MM belonging to that fifth scope, are very focused in technology itself and not in its capability of supporting todays HEI (as well as other types of Educational Institutions), in their challenges: dynamic and agile management, new teaching strategies, flexible formative portfolio and knowledge management. We are convicted that all the four remaining scopes can benefit if the HEI' Information Ecosystem stays optimized.

As a result of this study, as far as we know, none of the identified models has a sufficiently focused on the capability of the IS support complex, diversified, interoperable and dynamic organizational processes of HEI. In this perspective, a new model to fill the gap should be designed. This new model, 
should include the main influence factors with different weights depending on their relative importance and its development should be supported by rigorous scientific methods of conceptualization and validation. This model should also identify the IST key strategical areas of HEI and apply international standards for management of IST and HEI as well. Such MM will enable the evaluation of the HEI, in terms of their practices and strategies of IST, for supporting their institutional processes at all levels: organisational strategies, management, operative management, teaching and research. Thus, it empowers the capabilities of the HEI and its human capital (administrators, staff, teachers and students). In short, the contribution of this article is a Systematic Literature Review that makes the systematization of the knowledge regarding $\mathrm{MM}$, being focused in the educational area in general and Higher Education IS in particular.

\section{REFERENCES}

1. Zhihua, L. and W. Zhaojun, The application of maturity model in the schools' ICT project. In J. Feng (Ed.), Proceedings 2009 International Conference on Computational Intelligence and Software Engineering (pp. 14), 2009.

2. Saiti, A. and G. Prokopiadou, Impact of information and communication technologies on school administration: Research on the Greek schools of secondary education. Lecture Notes in Computer Science. 2009. 5693: p. 305-316.

3. Manjula, R. and J. Vaideeswaran, A New CMM-Quality Education (CMM-QE) Framework using SEI-CMM Approach and Calibrating for its Process Quality and Maturity using Structural Equation Modeling-PLS Approach. International Journal of Software Engineering and Its Applications, 2012. 6(4): p. 117-130.

4. Paulk, M., et al., Capability Maturity Model for Software Version 1.1. Software Engineering Institute, Carnegie Mellon University, CMU/SEI-93-TR-024, 1993.

5. Fraser, P., J. Moultrie, and M. Gregory, The use of maturity models/grids as a tool in assessing product development capability. In Proceedings of the IEEE International Engineering Management Conference (Cambridge, UK, Aug. 18-20). IEEE Engineering Management Society, Piscataway, NJ, . 2002: p. 244-249.

6. Nolan, R., Managing de computer resource: a stage hypotesis. Communications of de ACM, 1973. 16(7): p. 399405.

7. Gibson, C. and R. Nolan, Managing the Four stages of EDP Growth. Harvard Business Review, 1974. 1: p. 76-88.

8. Mettler, T., A Design Science Research Perspective on Maturity Models in Information Systems. University of St. Gallen, St. Gallen, 2009.

9. Caralli, R. and M. Knight, Maturity Models 101: A Primer for Applying Maturity Models to Smart Grid Security, Resilience, and Interoperability. Software Engineering Institute, Carnegie Mellon University, 2012.

10. Mettler, T. and P. Rohner, Situational Maturity Models as Instrumental Artifacts for Organizational Design. DESRIST09, Malvern, PA, USA, 2009.

11. Rocha, Á., Evolution of Information Systems and Technologies Maturity in Healthcare. International Journal of Healthcare Information Systems and Informatics, 2011 6(2): p. 28-36.

12. Carvalho, J.V., Á. Rocha, and A. Abreu, Main Influence Factors for Maturity of Hospital Information Systems. In Information Systems and Technologies (CISTI). Gran Canaria, España, 2016. 1: p. 1059-1064.

13. Carvalho, J.V., Á. Rocha, and A. Abreu, Maturity Models of Healthcare Information Systems and Technologies: a Literature Review. Journal of Medical Systems, 2016. 40(6): p. 1-10.

14. Webster, J. and R.T. Watson, Analyzing the Past to Prepare for the Future: Writing a Literature Review. MIS Quarterly, 2002. 26(2): p. 13-23.

15. Tranfield, D., D. D., and P. Smart, Towards a Methodology for De-veloping Evidence-Informed Management Knowledge by Means of Systematic Review. British Journal of Management, 2003. 14: p. 207-222.

16. SEI, CMMI ${ }^{\circledR}$ for Development, Version 1.3, Improving processes for developing better products and services. Tech. Rep. No. CMU/SEI-2010-TR-033), Carnegie Mellon University, 2010.

17. Rossi, R. and P.N. Mustaro, eQETIC: a maturity model for online education. Interdisciplinary Journal of e-Skills and Lifelong Learning, 2015. 11: p. 11-24.

18. Bass, J.M., An early-stage ICT maturity model derived from Ethiopian education institutions. International Journal of Education and Development using Information and Communication Technology, 7(1), 5., 2011. 7(1): p. 5-25.

19. Marshall, S. and G. Mitchell, An e-learning maturity model. Proceedings of the 19th Annual Conference of the Australian Society for Computers in Learning in Tertiary Education, Auckland, New Zealand, 2002.

20. Hadullo, K., R. Oboko, and E. Omwenga, A model for evaluating e-learning systems quality in higher education in developing countries. International Journal of Education and Development using Information and Communication Technology, 2017. 13(2): p. 185-204.

21. Iskander, G., A sequential exploratory design for the elearning maturity model in Middle Eastern countries. Diss. Middlesex University, 2013.

22. Alrasheedi, M. and L.F. Capretz, Applying CMM towards an m-learning context. Information Society (i-Society). International Conference on. IEEE 2013, 2013.

23. Marchewka, J.T., Applying the capability maturity model to assurance of learning. Communications of the IIMA, 2013. 13(1).

24. Fernando, S.D., A.N. Dahanayake, and H.G. Sol, A Holistic Maturity Model for IT Aligned University Education: IA$L M M$. In Proceedings of the IASTED International Conference on Education and Technology, 2005(4-6).

25. Neuhauser, C., A maturity model: Does it provide a path for online course design. The Journal of Interactive Online Learning 3.1, 2004: p. 1-17.

26. Gu, D., J. Chen, and W. Pu, Online course quality maturity model based on evening university and correspondence education (OCQMM). In Communication Software and Networks (ICCSN), 2011 IEEE 3rd International Conference, 2011: p. 5-9. 
27. Kenny, J., Strategy and the learning organization: a maturity model for the formation of strategy. The Learning Organization, 2006. 13(4): p. 353-368.

28. Clarke, J.A., K.J. Nelson, and I.D. Stoodley, The place of higher education institutions in assessing student engagement, success and retention: A maturity model to guide practice. 2013.

29. Newman, D. and D. Logan, Gartner Introduces the EIM Maturity Model. Gartner Research Publication, ID G00160425, 2008.

30. Middleton, G.R., A maturity model for intelligence training and education. Patrick Henry College 2007.

31. White, B., et al., Applicability of CMMI to the IS curriculum: a panel discussion. In Information Systems Education Conference (ISECON 2003), 2003: p. 1-5.

32. Thong, C.L., et al., Applying capability maturity model to curriculum design: A case study at private institution of higher learning in Malaysia In Proceedings of the World Congress on Engineering, 2012. 2.

33. Antonucci, Y.L., et al., Enterprise systems education: where are we? Where are we going? Journal of Information Systems Education, 2004. 15(3): p. 227-234.

34. Thompson, E., Towards a learning process maturity model. In $\mathrm{PhD}$ Workshop, 2004.

35. Mitasiunas, A. and L. Novickis, Enterprise SPICE based education capability maturity model. International Conference on Business Informatics Research. Springer, Berlin, Heidelberg, 2011, 2011.

36. Demir, C. and İ. Kocabaş, Project management maturity model (PMMM) in educational organizations. ProcediaSocial and Behavioral Sciences, 2010. 9: p. 1641-1645.

37. Silva, D.F.A. and R.B. Cabral, Maturity model for process of academic management. In Information Society (i-Society), 2010 International Conference on (pp. 444-448). IEEE., 2010.

38. Zhen, W. and Z. Xin-yu, An ITIL-based IT service management model for chinese universities. In Software Engineering Research, Management \& Applications, SERA 2007. 5th ACIS International Conference on IEEE., 2007: p. 493-497.

39. Garg, R.K. and M.P. Sharma, Capability Maturity Model for Higher Education. CKPIM - Business Review, 2014. 2(11): p. 17-28.

40. Boehm, M., M. Jasper, and O. Thomas, The Further Education Maturity Model: Development and Implementation of a Maturity Model for the Selection of Further Education Offerings in the Field of IT Management and IT Consulting. 2013.

41. Petrie, M.M.L., Towards an Engineering Education Capability Maturity Model. Proceedings of the 2004 American Society for Engineering Education Annual Conference \& Exposition Copyright C2004, American Society for Engineering Education, 2004. 9.

42. Lutteroth, C., et al., A maturity model for computing education. Proceedings of the ninth Australasian conference on Computing education. Australian Computer Society, Inc., 2007. 66: p. 107-114.

43. Reci, E. and A. Bollin, A Teaching Maturity Model for Informatics Teachers in Primary and Secondary Education. ISSEP 2016, 2016. 55.
44. Kajko-Mattsson, M., S. Forssander, and U. Olsson, Corrective maintenance maturity model (CM/sup 3/): maintainer's education and training. In Software Engineering, 2001. ICSE 2001. Proceedings of the 23rd International Conference on (pp. 610-619). IEEE, 2001.

45. Collofello, J.S. and C.H. Ng, Assessing the process maturity utilized in software engineering team project courses. Journal of Engineering Education, 2001. 90(1): p. 75-78.

46. Perez, S.E., Z. Martinaitis, and K.-H. Leitner, An intellectual capital maturity model (ICMM) to improve strategic management in European universities. Journal of Intellectual Capital, 2015. 16(2): p. 419-442.

47. Silva, P., Acessibilidade na web: nível de maturidade das instituições de ensino superior português. Diss. Mestrado. Instituto Universitário de Lisboa. Portugal, 2013.

48. Petrie, M., V. García, and G. Giraldo, Modelo de Registro y Acreditación de Instituciones de Educación Superior basado en el Modelo CMMI. In Seventh LACCEI Latin American and Caribbean Conference for Engineering and Technology (LACCEI'2009), San Cristóbal, Venezuela., 2009.

49. Putri, N.K.S. and H. Muljoredjo, The Use of green information technology governance model to determine capability maturity level in DKI Jakarta private higher education institutions Journal of Theoretical \& Applied Information Technology, 2014. 61(1).

50. Solar, M., J. Sabattin, and V. Parada, A maturity model for assessing the use of ICT in school education. Journal of Educational Technology \& Society, 2013. 16(1): p. 206-218.

51. Gu, D., J. Chen, and W. Pu, Online course quality maturity model based on evening university and correspondence education (OCQMM). In Communication Software and Networks (ICCSN), 2011 IEEE 3rd International Conference on (pp. 5-9). IEEE., 2011.

52. de Bruin, T., et al., Understanding the Main Phases of Developing a Maturity Assessment Model. 16th Australasian Conference on Information Systems (ACIS 2005), 2005.

53. Becker, J., R. Knackstedt, and J. Pöppelbuß, Developing Maturity Models for IT Management - A Procedure Model and its Application. Business \& Information Systems Engineering, 2009. 1(3): p. 213-222.

54. Mettler, T., Supply Management im Krankenhaus: Konstruktion und Evaluation eines konfigurierbaren Reifegradmodells zur zielgerichteten Gestaltung. $\mathrm{PhD}$ Thesis. Institute of Information Management. St. Gallen, University of St. Gallen., 2010. 